\title{
Cyclic GMP Levels and Guanylate Cyclase Activity in Pheromone- Sensitive Antennae of the Silkmoths Antheraea polyphemus and Bombyx mori
}

\author{
G. Ziegelberger, ${ }^{1}$ M. J. van den Berg, ${ }^{1}$ K.-E. Kaissling, ${ }^{1}$ S. Klumpp, ${ }^{2}$ and J. E. Schultz ${ }^{2}$ \\ ${ }^{1}$ Max-Planck-Institut für Verhaltensphysiologie, 8130 Seewiesen, and ²Pharmazeutisches Institut der Universität, 7400 \\ Tübingen, Federal Republic of Germany
}

Female sex pheromones applied to freshly isolated, living antennae of male Antheraea polyphemus and Bombyx mori led to an increase of CGMP. A 1:1 mixture of 2 pheromone components of Antheraea polyphemus blown for $10 \mathrm{sec}$ in physiological concentrations over their antennal branches raised cGMP levels about 1.34-fold ( \pm 0.08 SEM, $n=23$ ) from a basal level of $3.0 \pm 0.6(\mathrm{SEM}, n=20) \mathrm{pmol} / \mathrm{mg}$ protein. Similarly, bombykol elicited a 1.29 -fold $( \pm 0.13$ SEM, $n=23$ ) cGMP increase in antennae of male Bombyx mori from a basal level of $2.7 \pm 0.5($ SEM, $n=24) \mathrm{pmol} / \mathrm{mg}$ protein. No cross-sensitivity was found with respect to pheromones from either species. In antennae of female silkmoths, the cGMP response was missing upon stimulation with their own respective pheromones according to the known lack of pheromone receptor cells in the female. cAMP levels in the male antennae of $14.2 \pm 2.9$ (SEM, $n=4) \mathrm{pmol} / \mathrm{mg}$ protein in $A$. polyphemus and $15.0 \pm 3.0(\mathrm{SEM}, n=5) \mathrm{pmol} / \mathrm{mg}$ protein in $B$. mori were not affected by pheromone stimulation.

Within 1-60 sec, the extent of cGMP increase in $B$. mori was independent of the duration of pheromone exposure. The levels of CGMP in pheromone-stimulated antennae of both species remained elevated for at least $10 \mathrm{~min}$, i.e., much longer than the duration of the receptor potential measured in single-cell recordings.

Guanylate cyclase activity was identified in homogenates of male and female antennae from both species. The $K_{m}$ of the guanylate cyclase from male $B$. mori for the preferential substrate MnGTP was $175 \mu \mathrm{M}$. Specific activity at the pH optimum of 8.25 was $5-30 \mathrm{pmol} \times \mathrm{min}^{-1} \times \mathrm{mg}^{-1}$. About half of total guanylate cyclase activity was soluble. SH-group blocking agents inhibited, whereas dithiothreitol and glutathion doubled enzyme activity. The enzyme was inhibited by antibodies raised against soluble guanylate cyclase from bovine lung.

To localize the increase of cGMP in the antennae, sensory hairs of male A. polyphemus which contain only the receptive dendrites of the olfactory neurons, were isolated. Neither changes in cGMP concentrations upon pheromone stimulation nor guanylate cyclase activity were found in the den-

\footnotetext{
Received June 20, 1989; revised Sept. 7, 1989; accepted Oct. 4, 1989.

We wish to thank Anka Günzel for her untiring help in all technical work, Ute Lauterfeld for drawing and photography, Less Williams for correcting the text, and Inge Susann Rössel for typing the manuscript. This work was supported in part by the Deutsche Forschungsgemeinschaft (KL 601/1-1, 1-2).

Correspondence should be addressed to Dr. Gunde Ziegelberger at the above address.

Copyright (C) 1990 Society for Neuroscience $0270-6474 / 90 / 041217-09 \$ 02.00 / 0$
}

drite preparation. This indicates that cGMP is possibly produced within the soma of the olfactory neurons or within the surrounding auxiliary cells.

This study leads to the conclusion that cGMP is not involved in the transduction process generating the receptor potential. Both the down-regulation of the cGMP level and the recovery of the nerve impulse response after a conditioning stimulus were impaired in isolated antennae. This correlation might indicate a physiological role for cGMP in the setting of the parameters of the nerve impulse response.

Cyclic nucleotides are believed to participate in the regulation of membrane conductances in different sensory transduction systems of vertebrates, e.g., in visual, gustatory, and olfactory receptor cells. In visual transduction, cGMP dircetly gatcs ion channels in the outer segment of rods and cones (reviewed in Lamb, 1986; Stryer, 1986). In olfactory cilia of frog, an odorantsensitive adenylate cyclase has been characterized (reviewed in Pace et al., 1985; Anholt, 1987; Lancet and Pace, 1987), and patch-clamp studies on these cilia indicated a gating of ion channels by cAMP or cGMP (Nakamura and Gold, 1987). In taste cells, $\mathrm{K}^{+}$channels are closed by phosphorylation due to a cAMPdependent protein kinase (Avenet et al., 1988; Tonosaki and Funakoshi, 1988). Apart from a function in intracellular signal amplification, cyclic nucleotides can also play a role in longterm modification of receptors or ion channels via reversible phosphorylation cycles. Phosphorylation of membrane proteins by cyclic nucleotide-dependent protein kinases has been reported to cause desensitization in different signal-transduction systems of vertebrates (Sibley et al., 1984; Huganir et al., 1986).

In this study we investigated the possible role of cyclic nucleotides for olfactory processes in the antennae of the silkmoths Antheraea polyphemus and Bombyx mori. We tried to determine whether olfactory stimuli change cyclic nucleotide levels in the antennae and whether such effects are involved in the transduction process or in other olfactory functions. As olfactory stimuli, the following components of the female pheromone were used: (E,Z)-10,12-hexadecadienol (bombykol) in $B$. mori and a 1:1 mixture of (E,Z)-6,11-hexadecadienyl acetate (AC) and (E,Z)-6,11-hexadecadienal (AL) in A. polyphemus.

Male moths receive each component of the female sex pheromone by means of several tens of thousands of sensory neurons on the antennae (Steinbrecht, 1970; Meng et al., 1989). It is most likely that the outer dendrites of these cells are equipped with homogenous populations of pheromone receptor molecules. An action potential in a sensory neuron can be triggered 
by a single pheromone molecule (reviewed in Kaissling, 1986, 1987). This outstanding sensitivity could, in principle, be achieved by purely electrical amplification in these cells. In silkmoths, an elementary receptor potential triggering a nerve impulse could result from the opening of a single ion channel responding to a single pheromone molecule (Kaissling and Thorson, 1980). This mechanism of direct gating by the stimulus molecule would work without metabolic amplification of the signal. Data obtained in vertebrates by single-channel recording using cilia or intact olfactory receptor cells support both types of transduction mechanisms, direct gating of ion channels or gating via second messengers (Vodyanoy and Murphy, 1983; Nakamura and Gold, 1987; Trotier and MacLeod, 1987; Labrarca et al., 1988).

As a first step in studying the role of cyclic nucleotides in pheromone reception, the levels of cAMP and cGMP and the activity of antennal guanylate cyclase (GC) were measured before and after pheromone stimulation. The results are discussed in the context of electrophysiological responses of the olfactory receptor cells (Schneider et al., 1967; Zack, 1979; Kaissling, 1986, 1987; Zack Strausfeld and Kaissling, 1986; Kaissling et al., 1987). Additional electrophysiological measurements were made to study the changes in concentration of cyclic nucleotides and recovery after adaptation under identical stimulus conditions in intact animals and isolated antennae.

\section{Materials and Methods}

Animals. Pupae of $A$. polyphemus (Cramer) were supplied by M. Furr (Germantown, TN) and pupae of $B$. mori were from the Istituto Sperimentale per la Bachicoltura (Padova, Italy). The cocoons were stored at $4^{\circ} \mathrm{C}$, and the moths were allowed to develop at room temperature.

Tissue preparation and quantitation of cyclic nucleotides. Either intact moths were stimulated with pheromone or antennae were freshly cut from the animals, quickly transferred into plastic test tubes, and exposed to an airstream for stimulation $(100 \mathrm{ml} / \mathrm{sec})$. Pheromones were added by insertion of a filter paper $\left(1.2 \mathrm{~cm}^{2}\right)$ loaded with the indicated quantities into the air flow (for details, scc Zack Strausfcld and Kaissling, 1986). Usually, after $10 \mathrm{sec}$ of stimulation the antennae were frozen immediately in liquid nitrogen and $500 \mu \mathrm{l}$ of $6 \%$ cold trichloroacetic acid (TCA) was added. Stimulation was continued in order to keep the cells in an excited state until the TCA was added. The frozen specimens were stored at $20^{\circ} \mathrm{C}$ until cyclic nucleotide determinations were carried out.

Throughout this study, pheromone-stimulated antennae of one side were compared with those of the other side, which were treated with "blank" air as a control stimulus. Thus, we obtained paired sets of data which are represented in the figures as the ratios of stimulated over unstimulated values. A single antenna of male $A$. polyphemus was sufficient for determination of cAMP and cGMP in duplicates. Because of the considerably smaller size, routinely 2 antennae of female $A$. polyphemus and 3 of male and female $B$. mori were pooled separately from either side of the moth for individual experiments.

The sensory hairs of male $A$. polyphemus were isolated as described by Klein and Keil (1984). The side branches were cut from 20 left antennae, and combined and stimulated with pheromone for $30 \mathrm{sec}$. The hairs were isolated and suspended in $500 \mu \mathrm{l} 6 \%$ cold TCA, homogenized at $4^{\circ} \mathrm{C}$ for $20 \mathrm{~min}$, and treated further as detailed below. Controls from the right antennae were handled identically.

For extraction of cyclic nucleotides, frozen antennae were homogenized in $500 \mu \mathrm{l} \mathrm{TCA}$ at $4^{\circ} \mathrm{C}$ for $5 \mathrm{~min}$ with a motor-driven glass homogenizer with plastic plunger which broke the cuticle effectively. The homogenate was centrifuged at $5000 \times g$ for $15 \mathrm{~min}$. The supernatant was extracted 4 times with 5 volumes of water-saturated ether and was lyophilized. For protein determination (Lowry et al., 1951; Bradford 1976), the pellet was suspended in $10 \mathrm{~mm}$ Tris- $\mathrm{HCl}, \mathrm{pH} 7.5$.

Guanylate cyclase activity. Enzyme activities were measured in antennae homogenized in $10 \mathrm{~mm}$ Mops buffer, $\mathrm{pH}$ 7.5. Guanylate cyclase was assayed at $37^{\circ} \mathrm{C}$ in $50 \mu$ l containing $30 \mathrm{mM}$ Tris- $\mathrm{HCl}$ at $\mathrm{pH} 8.0,2$ mM $\mathrm{Mn}^{2+}, 1 \mathrm{~mm}$ cGMP [including $5 \mathrm{nCi}$ of $\left(8-{ }^{3} \mathrm{H}\right) \mathrm{cGMP}$ to monitor yield during subsequent purification], $1.5 \mathrm{~mm}$ phosphoenolpyruvate, 1 U pyruvate kinase, and $0.1 \%$ lubrol PX. Homogenates contained up to $50 \mu \mathrm{g}$ protein. The reaction was started by addition of $2 \mathrm{~mm}$ GTP $[0.5$ $\mu \mathrm{Ci}\left(\alpha^{-32} \mathrm{P}\right) \mathrm{GTP}$. Incubation was stopped by addition of $0.5 \mathrm{ml} 120 \mathrm{~mm}$ $\mathrm{Zn}$-acetate and $0.6 \mathrm{ml} 120 \mathrm{mM} \mathrm{Na}_{2} \mathrm{CO}_{3}$. cGMP was purified on neutral alumina columns under acid conditions and desorbed by ammonium formate (Jakobs et al., 1976). No cGMP was found when exogenous phosphodiesterase was added after the incubations.

Electrophysiological techniques. Recordings from either isolated branches or intact animals were made according to Zack Strausfeld and Kaissling (1986). The receptor potential amplitude was defined as the maximum deviation from the baseline during the $2 \mathrm{sec}$ stimulation period, while the nerve impulse response was determined by averaging the intervals between 11 consecutive impulses at maximum frequency. Either one of the 2 known pheromone components, i.e., AC or AI, was used as stimuli to test the receptor cell responses. Pieces of filter paper loaded with a pheromone component were inserted in a glass cartridge, through which air $(100 \mathrm{ml} / \mathrm{sec})$ was directed during $2 \mathrm{sec}$ stimulation period. This cartridge was placed $5 \mathrm{~cm}$ in front of the antenna.

During an experiment, the responses of unadapted cells were first measured by stimulating them with papers luaded with $10^{4}, 10^{3}, 10^{2}$, or $10^{-1} \mu \mathrm{g} \mathrm{AL}$ or $\mathrm{AC}$ (in ascending order). Then, at time 0 , either a conditioning stimulus of $1 \mu \mathrm{g} \mathrm{AC}$ was given or pure air as a control. At varying times after conditioning, the cells were tested with $10^{-2} \mu \mathrm{g} \mathrm{AC}$ $10^{-1} \mu \mathrm{g} \mathrm{AL}$, and $10^{-1} \mu \mathrm{g} \mathrm{AC}$. The recovery was then defined as the ratio of the response after time 0 and the response (same substance and concentration) before time 0 . With every individual at least one conditioning experiment and one control experiment were done, using hairs from a different branch for each experiment. Finally, the corrected recovery was defined as the ratio of the recovery during a conditioning experiment and the mean recovery in the control experiment as found with the same animal.

Reagents. Cyclic nucleotide concentrations were determined using a commercial radioimmunoassay kit for cAMP and cGMP (New England Nuclear). The identity of CAMP and cGMP was ascertained by degradation with cyclic nucleotide phosphodiesterase (Boehringer-Mannheim). Antibodies against soluble GC from bovine lung were kindly provided by Dr. E. Böhme (Berlin). Radiochemicals were from Amersham; all other chemicals were of analytical grade and purchased from either Boehringer-Mannheim, Merck, or Sigma.

\section{Results}

\section{Cyclic nucleotides}

The contents of cyclic nucleotides measured separately in each of both antennae of a single moth were almost identical (see Figs. 1,2); however, a rather high variability between individual insects was observed (Table 1). Therefore, in all experiments one antenna of each animal was stimulated with pheromone while the other one received a control stimulus with pure air. Homologous pheromone stimulation of male and female $A$. polyphemus and $B$. mori did not cause changes in cAMP levels, as shown by a ratio of around unity between stimulated and unstimulated antennae of individual insects (Fig. 1, $a, b$ ).

An increase of cGMP levels was found upon homologous pheromone stimulation of intact animals and freshly isolated antennae of males of $A$. polyphemus and $B$. mori (shown for isolated antennae in Fig. 2). This increase was statistically significant above controls without pheromone if all values, observed at physiological pheromone concentrations below saturation of the receptor potential amplitude (between 0.01 and $100 \mu \mathrm{g}$ of pheromone per filter paper; see Zack, 1979; Kaissling et al., 1987), were combined. The average increase was 1.34fold \pm 0.08 SEM $(n=23)$ for males of $A$. polyphemus and 1.29fold $\pm 0.13 \operatorname{SEM}(n=23)$ in B. mori. Due to the increased variability of cGMP values after pheromone stimulation, a clear dose-response relationship was not established. In females, cGMP levels were not significantly affected by phcromone stimulation (Fig. 1c). The ratios between stimulated and unstimu- 
males, cAMP

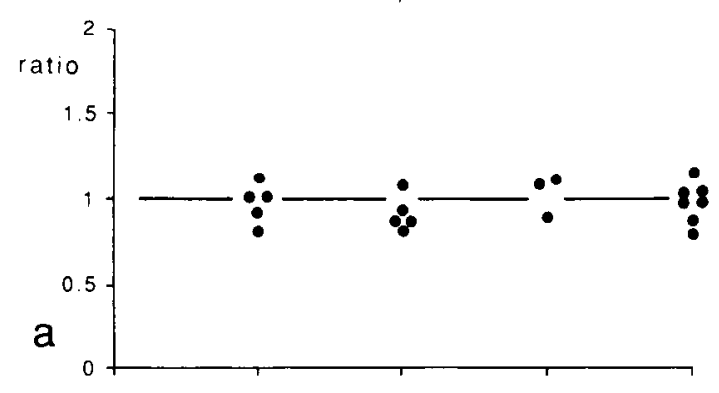

females, cAMP
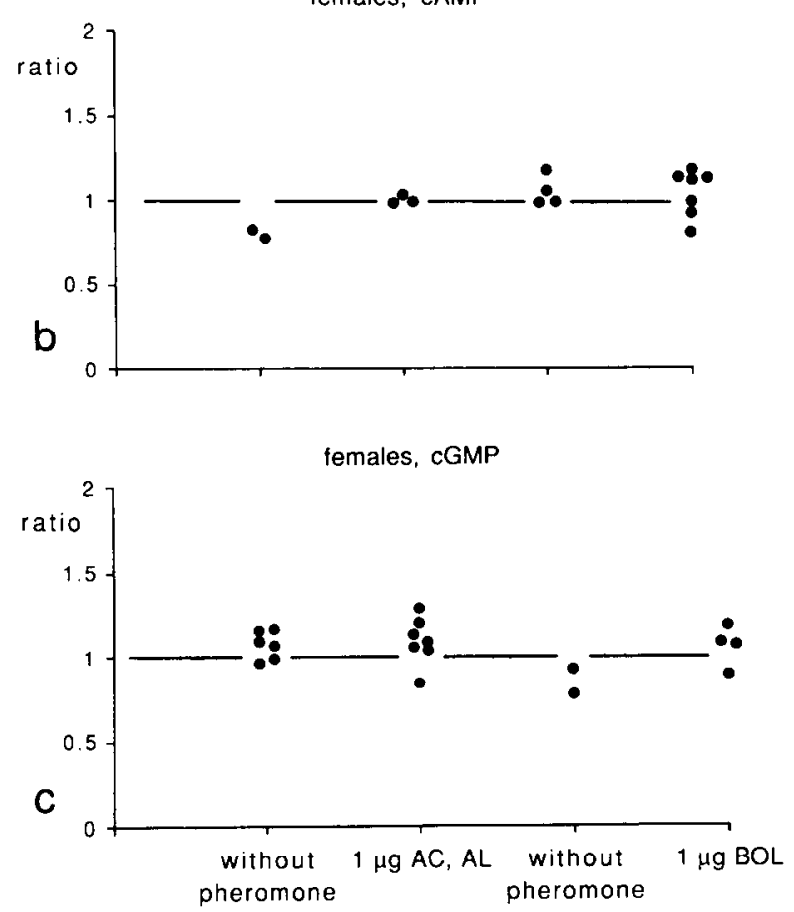

Antheraea polyphemus

Bombyx mori

Figure $1 . \quad a$ and $b$, cAMP levels and pheromone stimulation in $A$. polyphemus and $B$. mori. cAMP ratios between freshly isolated right and left antennae of male $(a)$ and female $(b)$ individuals. The ratio between both unstimulated antennae in males was $1.01 \pm 0.04$ (SEM, $n=8)$ and in females, $0.96 \pm 0.06$ (SEM, $n=6$ ). In both species together the ratio between pheromone-stimulated and unstimulated antennae in males was $0.97 \pm 0.03$ (SEM, $n=12$ ) and in femalcs, $1.04 \pm 0.03$ (SEM, $n=10$ ). $c$, cGMP ratios in females. Between unstimulated antennae of both species the ratio was $1.03 \pm 0.05$ (SEM, $n=8$ ), and between the pheromone-stimulated and unstimulated antennae, it was $1.10 \pm 0.04$ (SEM, $n=11$ ). In $a-c$, no significant increase ( $t$ test, $p>$ $0.05)$.

lated levels of cGMP in the female antennae of both species were $1.10 \pm 0.04(\mathrm{SEM}, n=11)$.

Next, we used heterologous stimulation to test whether the increase in cGMP levels in male moths was specific for the sex pheromone of the same species. The ratio of cGMP levels in antennae from $A$. polyphemus stimulated by bombykol was 1.00 $\pm 0.05(\mathrm{SEM}, n=5)$ and in antennae from $B$. mor $i$ stimulated by pheromones from $A$. polyphemus, $1.01 \pm 0.03$ (SEM, $n=$ 4 ), i.e., no cross-reactivity was found between $A$. polyphemus and $B$. mori pheromones (Fig. 2). Therefore, we conclude that the increase in cGMP in the antennae of both moths is elicited
Antheraea polyphemus, cGMP

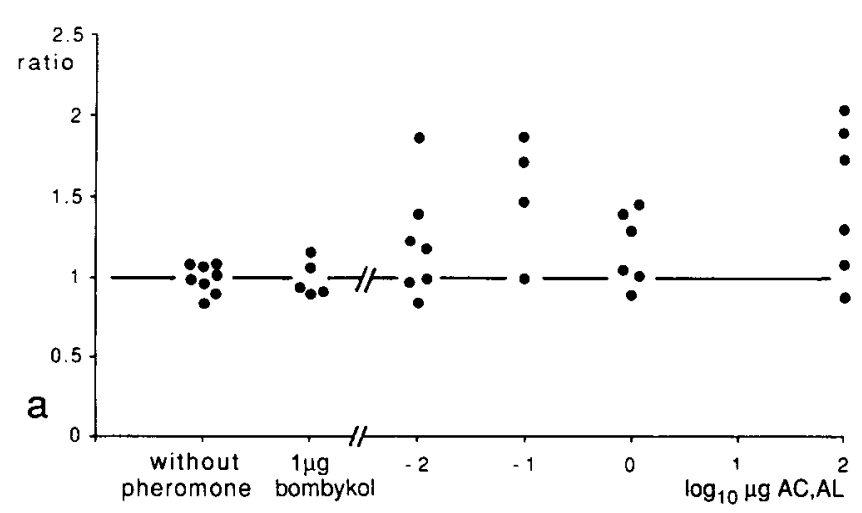

Bombyx mori, cGMP

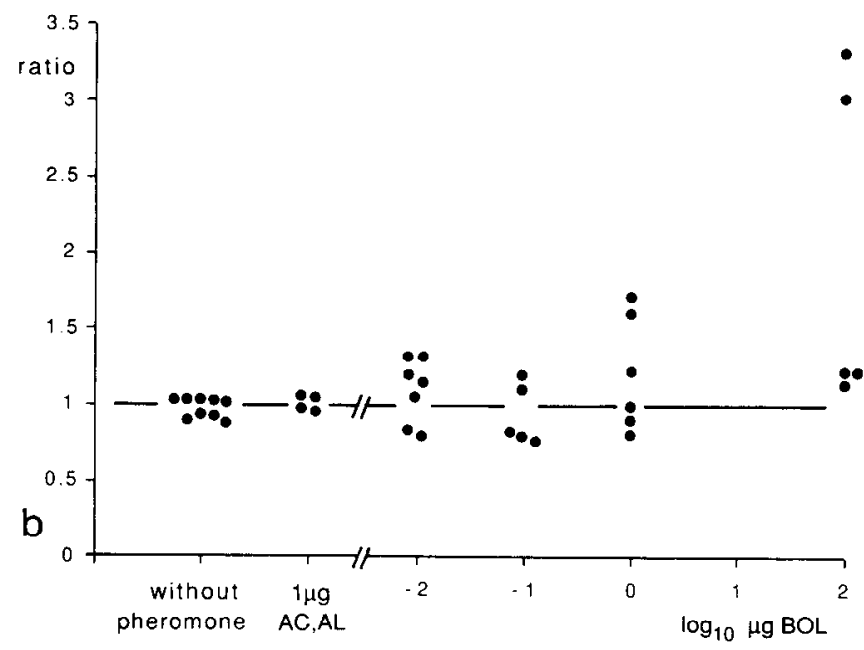

Figure 2. Dose-response relationships of cGMP ratios between isolated right and left antennae of male $A$. polyphemus $(a)$ and $B$. mori $(b)$. The ratio between both unstimulated antennae was $1.00 \pm 0.03$ (SEM, $n=8)$ in $A$. polyphemus and $1.00 \pm 0.02(\mathrm{SEM}, n=9)$ in $R$. mori. In A. polyphemus the ratio between $1 \mu \mathrm{g}$ bombykol-stimulated and unstimulated antennae was $1.00 \pm 0.05(\mathrm{SEM}, n=5)$, and in cross-stimulated $B$. mori, it was $1.01 \pm 0.03$ (SEM, $n=4)$. Homologous stimulation with $0.01,0.1,1.0$, and $100 \mu \mathrm{g}$ pheromone per filter paper led to an average ratio of $1.34 \pm 0.08$ (SEM, $n=23$ ) in $A$. polyphemus and 1.29 $\perp 0.13$ (SEM, $n=23$ ) in B. mori; i.e., significant increase in both species ( $t$ test, $p<0.01$ ).

by the interaction of the homologous female sex pheromone with the specific receptor cells in the male antenna.

In addition, we investigated the influence of stimulus duration on the cGMP response to pheromone in male $B$. mori antennae stimulated with $1 \mu \mathrm{g}$ bombykol on filter paper. cGMP levels were elevated after stimuli of $1 \mathrm{sec}$ up to $60 \mathrm{sec}$, but they showed no significant alteration depending on stimulus duration (Fig. 3).

In a further experimental series, we attempted to follow the decrease of cGMP levels in freshly isolated antennae of each animal after termination of pheromone stimulation. In one set of experiments, both isolated antennae of each animal were stimulated by $1 \mu \mathrm{g}$ per filter paper of the respective pheromones for 10 sec. One antenna was then frozen in liquid nitrogen and the other, paired antenna was kept without pheromone for various periods of time. Neither in antennae from $A$. polyphemus nor from $B$. mori did we observe a decrease in cGMP to the 
Bombyx mori, cGMP

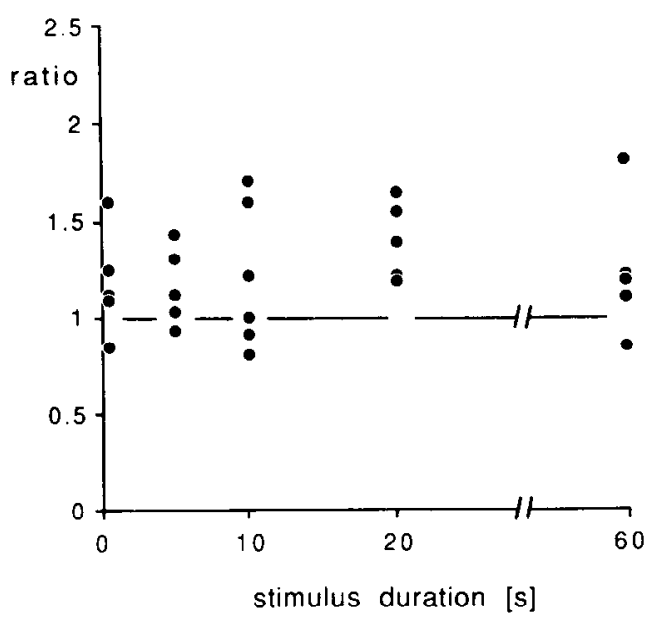

Figure 3. cGMP ratios between isolated right and left antennae of males of $B$. mori, stimulated with $1 \mu \mathrm{g}$ bombykol per filter paper for $1-$ $60 \mathrm{sec}$. Significant increase of $1.24 \pm 0.05$ (SEM, $n=26 ; t$ test, $p<$ $0.01)$.

expected prestimulation levels. The latter can be estimated from the experiments with pheromone stimulation in Figure 2 for $A$. polyphemus and $B$. mori and is indicated in Figure 4 by hatched lines. Actually, the cGMP concentrations between 5 and 30 min after cessation of stimulation showed a significant secondary increase (Fig. 4, filled symbols).

A separate set of these experiments was carried out with intact animals. The silkmoths were exposed to pheromones for $10 \mathrm{sec}$, and one antenna was cut off and frozen and the other was left on the animal for up to $30 \mathrm{~min}$ without further stimulation. cGMP levels showed no secondary increase; they appeared unaltered during the poststimulation periods (Fig. 4, open symbols) and showed no significant decrease to the prestimulation value for at least $10 \mathrm{~min}$.

In order to localize the increase of cGMP in the antennae of male $A$. polyphemus, we isolated the sensory hairs which contain only the receptive dendrites of the olfactory neurons from the antennal branches after pheromone stimulation, using the method of Klein and Keil (1984). The cGMP content in sensory hairs isolated from 20 right antennae stimulated with air for $30 \mathrm{sec}$ (controls) is compared with the cGMP content in sensory hairs of the pheromone-stimulated ( $1 \mu \mathrm{g} \mathrm{AC}$ and $\mathrm{AL}$ per filter paper
Antheraea polyphemus, cGMP
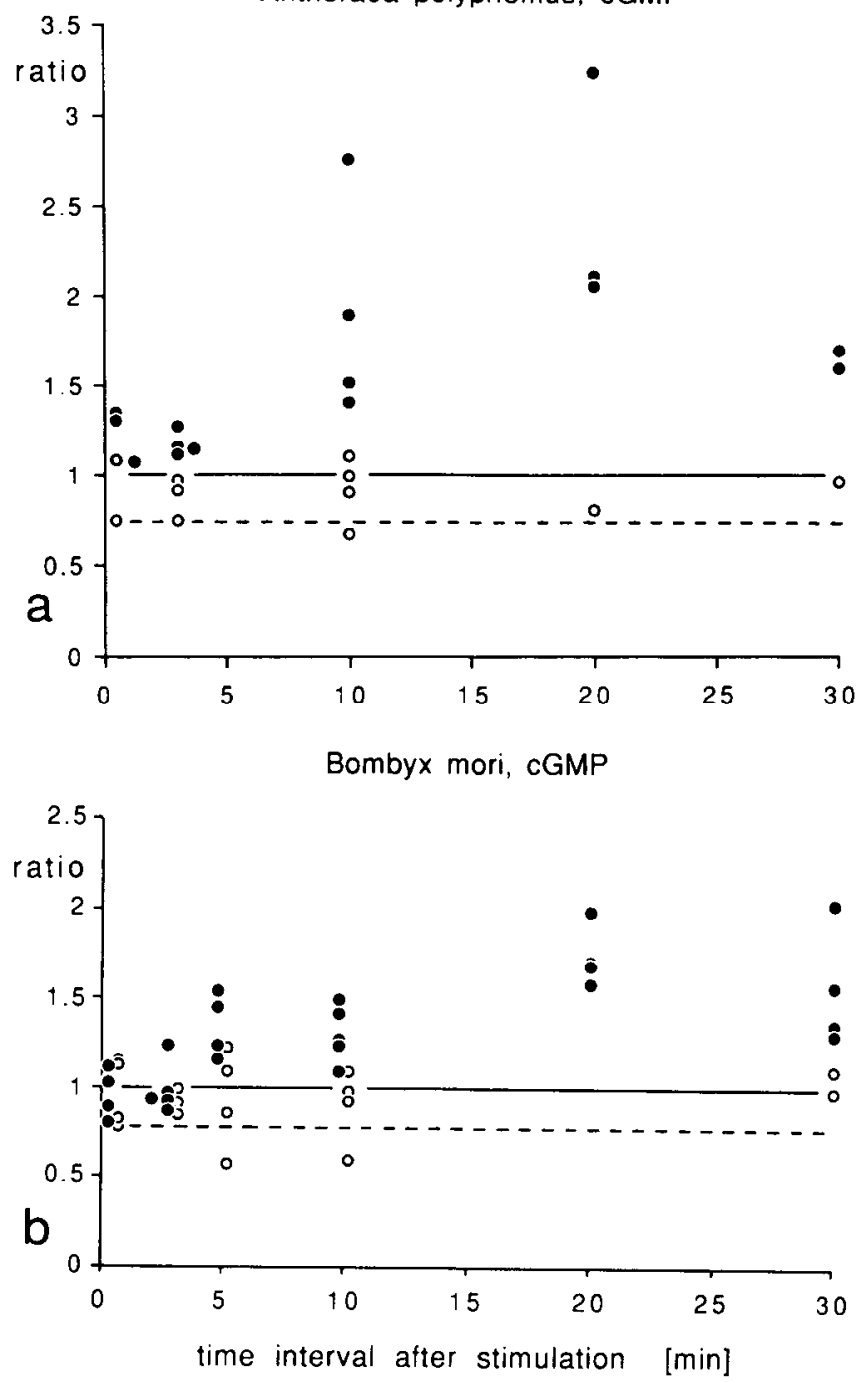

Figure 4. Poststimulation behavior of cGMP ratios between right and left antennae of male $A$. polyphemus ( $a$ ) and $B$. mori $(b)$. Both antennae were stimulated with $1 \mu \mathrm{g}$ pheromone per filter paper for $10 \mathrm{sec}$. One antenna was tested for periods between 0.5 and $30 \mathrm{~min}$ after stimulation, and the paired antenna was tested immediately after stimulation. (O), isolated antennae; $(O)$, intact animals. Hatched lines indicate prestimulation level of cGMP as expected from the average responses of cGMP in Figure 2. Significant secondary increase in isolated antennae was observed between 5 and $30 \mathrm{~min}$ after stimulation ( $t$ test, $p<0.01$ ).

\begin{tabular}{|c|c|c|c|c|}
\hline \multirow[b]{3}{*}{ Nucleotide } & \multicolumn{4}{|l|}{ Content (pmol) } \\
\hline & \multicolumn{2}{|c|}{ Antheraea polyphemus } & \multicolumn{2}{|l|}{ Bombyx mori } \\
\hline & Male & Female & Male & Female \\
\hline \multicolumn{5}{|l|}{ cAMP } \\
\hline per antenna & $0.92 \pm 0.14(8)$ & $0.27 \pm 0.05(5)$ & $0.24 \pm 0.04(8)$ & $0.19 \pm 0.02(9)$ \\
\hline per mg protein & $14.24 \pm 2.87(4)$ & $9.05 \pm 2.16(4)$ & $15.00 \pm 3.02(5)$ & $22.04 \pm 4.40(8)$ \\
\hline \multicolumn{5}{|l|}{ cGMP } \\
\hline per antenna & $0.10 \pm 0.02(44)$ & $0.02 \pm 0.00(11)$ & $0.04 \pm 0.00(47)$ & $0.01 \pm 0.00(6)$ \\
\hline per mg protein & $3.00 \pm 0.55(20)$ & $0.65 \pm 0.17(9)$ & $2.70 \pm 0.48(24)$ & $0.56 \pm 0.16(4)$ \\
\hline
\end{tabular}

Means \pm SEM are given, numbers of independent assays are in parentheses. In male A. polyphemus only the antennal branches of a single antenna were used for cyclic nucleotide and protein (Lowry et al., 1951) determination. In female $A$. polyphemus, male and female $B$. mori each assay was performed with groups of 2 or 3 antennae. 


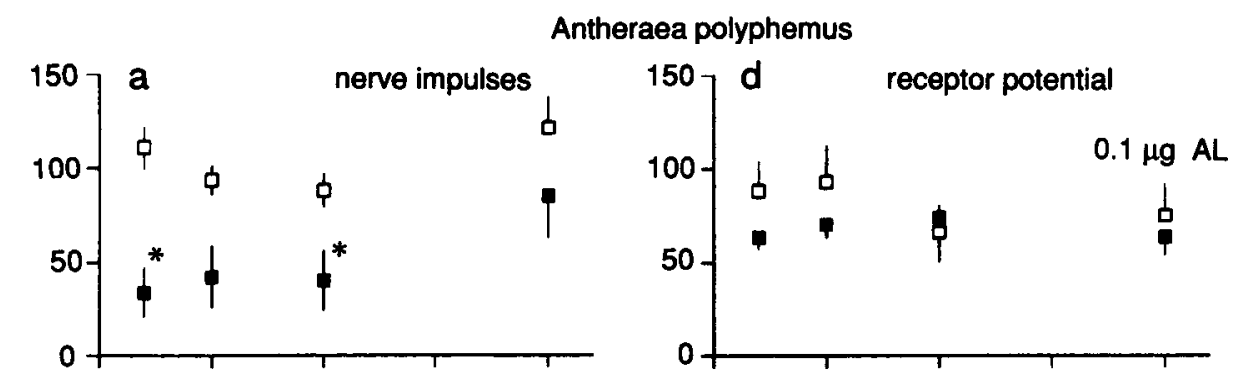

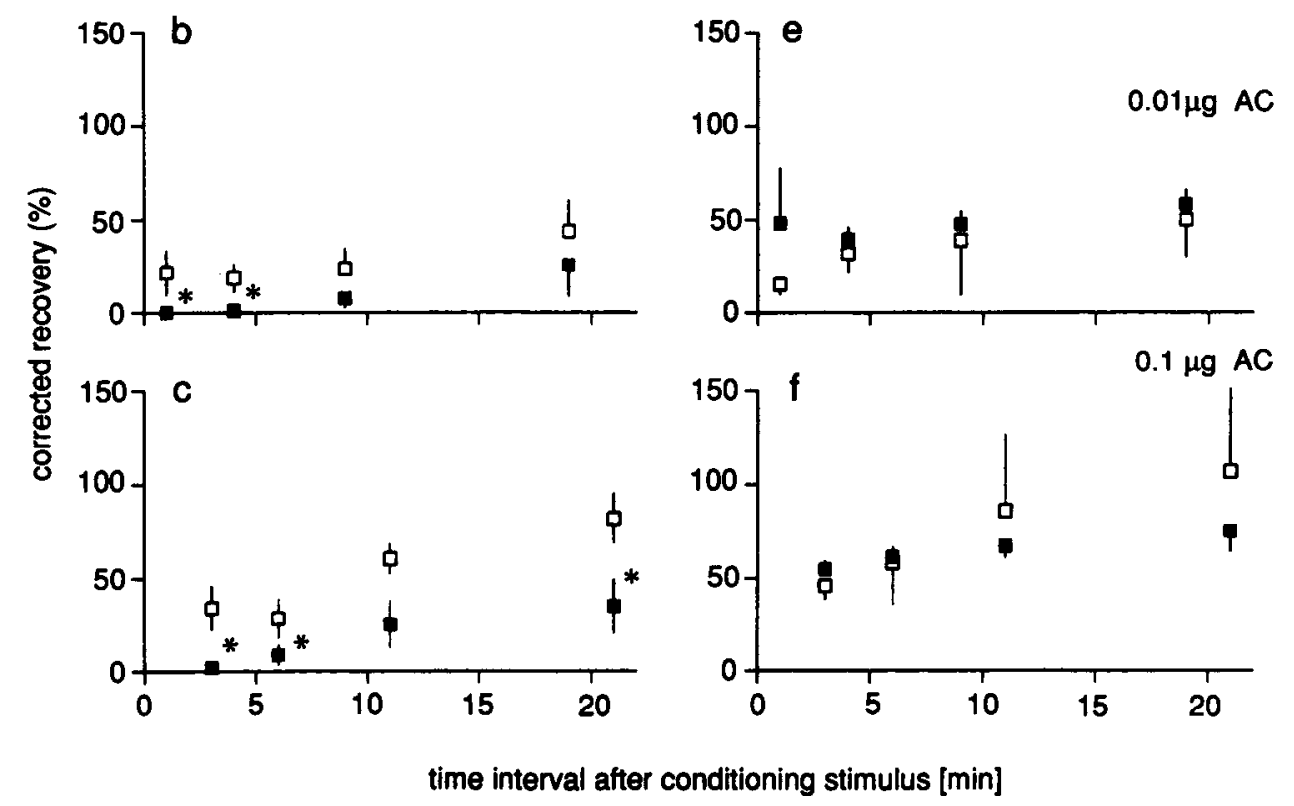

Figure 5. Adaptation and recovery of receptor cell responses recorded from sensilla trichodea of intact animals (open squares) and isolated antennal branches (filled squares) of $A$. polyphemus. Corrected recovery values $( \pm$ SEM) of nerve impulse responses $(a-c)$ and accompanying receptor potentials $(d-f)$. After the conditioning stimulus ( $1 \mu \mathrm{g} \mathrm{AC/filter}$ paper), each preparation was tested 4 times within 20 min with 3 test stimuli applicd in the following sequence: 0.01 $\mu \mathrm{g} \mathrm{AC}(c, f), 0.1 \mu \mathrm{g} \mathrm{AL}(a, d)$, and 0.1 $\mu \mathrm{g} \mathrm{AC}(b, e)$ per filter paper. Asterisks indicate significant differences between isolated antenna and intact animal at a given recovery time (Mann-Whitney $U$ test, $\alpha=0.05$ ). Each experiment plus control was repeated either 10 (isolated antennae) or 9 times (intact animals). for $30 \mathrm{sec}$ ) left antennae. In 2 independent experiments, cGMP was found to be present in the sensory hairs $(0.53$ and 0.36 $\mathrm{pmol} / \mathrm{mg}$ protein, in contrast to $3.00 \pm 0.55 \mathrm{pmol} / \mathrm{mg}$ protein in antennal branches), but we did not find an increase in cGMP there.

\section{Electrophysiology}

A difference between intact animals and isolated antennal branches was also seen in electrophysiological experiments on adaptation with $A$. polyphemus males (Fig. 5). Both preparations showed equal responsiveness in the unadapted state (Table 2). However, a conditioning stimulus of $1 \mu \mathrm{g} \mathrm{AC}$ per filter paper produced stronger adaptation and cross-adaptation of the nerve impulse response and slower recovery in isolated branches than in intact animals. This had been observed in a single experiment by Zack (1979) and could be confirmed in our experiments. The effect is clearly demonstrated by the reduced peak frequency of nerve impulses of the AC-cells, after conditioning (at time 0 ) when tested with $\mathrm{AC}$, and by its slow and incomplete increase during the first $20 \mathrm{~min}$ of recovery (Fig. 5, $b, c$ ). The AL-cell was tested with $0.1 \mu \mathrm{g} \mathrm{AL}$ and showed no significant crossadaptation of nerve impulse response due to conditioning with $\mathrm{AC}$ in the intact animal but a clear effect in the isolated antennal branch (Fig. $5 a$ ). Adaptation of the receptor potential amplitude was less pronounced than for the nerve impulses (Fig. 5, $d-f$ ). In contrast to the one antenna tested by Zack (1979), no sig- nificant difference in adaptation and recovery between intact animals and isolated antennae was observed for the AC-cell (Fig. 5, $e, f$ ) or the cross-adapted AL-cell (Fig. 5d). It should be noted that in accordance with earlier observations (Kaissling, 1972; Zack, 1979; Kaissling et al., 1987), the responses to smaller test stimuli were more adapted and recovered more slowly than those to the stronger test stimuli.

\section{Guanylate cyclase}

The existence of cGMP in the antennae is indicative of the presence of the corresponding enzyme which produces cGMP from GTP. We were able to identify a GC activity in homog-

Table 2. Comparison of unadapted nerve impulse responses in intact animals and isolated antennae of $A$. polyphemus

\begin{tabular}{lcc} 
& $\begin{array}{c}\text { Intact animals } \\
(n-15)\end{array}$ & $\begin{array}{l}\text { Isolated antennae } \\
(n=20)\end{array}$ \\
\hline $\mathrm{AL} 10^{-1} \mu \mathrm{g}$ & $104.6(6.3)$ & $106.6(13.2)$ \\
$\mathrm{AC} 10^{-2} \mu \mathrm{g}$ & $74.1(6.9)$ & $89.4(6.3)$ \\
$\mathrm{AC} 10^{-1} \mu \mathrm{g}$ & $103.5(6.8)$ & $126.3(13.4)$
\end{tabular}

Average peak impulse frequencies (impulses/sec), elicited by test stimuli (AL, AC) applied before conditioning stimuli or respective control stimuli were given. Same set of experiments as shown in Figure 5. $n=$ Number of cells tested. SEM in parentheses. The differences between both preparations were not significant $(t$ test, $p>0.05$ ). 

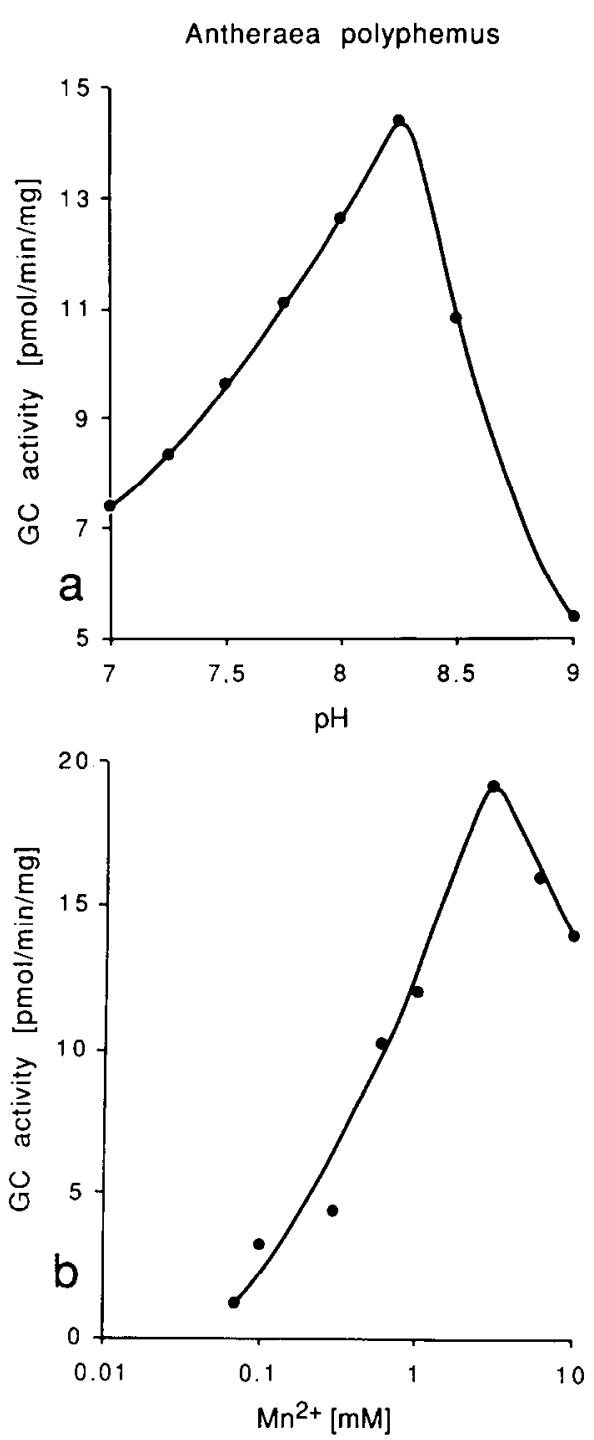

Figure 6. $\mathrm{pH}$ dependence (a) and cofactor requirement $(b)$ of $\mathrm{GC}$ in homogenates from $B$. mori antennae. Enzyme activity was measured under standard conditions except for varying the $\mathrm{pH}$ value of the incubation mixture $(a)$ or changing the $\mathrm{Mn}^{2+}$ concentration $(b)$.

enates from male as well as female antennae from both species. Irrespective of the source of the antennae, i.e., from male or female and from A. polyphemus or B. mori, the specific activity of GC in the homogenates using MnGTP as a substrate was in the range of 5-30 pmol $\times \mathrm{min}^{-1} \times \mathrm{mg}^{-1}$. In contrast to the presence of cGMP in sensory hairs, we could not find guanylate cyclase activity in homogenates prepared from isolated hairs.

Several control incubations were carried out to identify GC activity. Only GTP was sequestered as a substrate, ATP was not converted to cAMP. Irrespective of $\mathrm{Mn}^{2+}$ or $\mathrm{Mg}^{2+}$ as cofactor, the presence of $0.1-1 \%$ lubrol PX, $5 \mathrm{mM} \mathrm{F}^{-}, 100 \mu \mathrm{M} \mathrm{Al}^{3+}$, or $100 \mu \mathrm{M} \mathrm{Ca}^{2+}$ plus $1 \mu \mathrm{g}$ calmodulin/sample, we could not find any adenylate cyclase activity. The reaction product cGMP was completely degradable by addition of an excess of phosphodiesterase at the end of the enzyme assay. GC activity increased linearly with increasing protein concentration (5-50 $\mu \mathrm{g} /$ tube) and incubation time (up to $30 \mathrm{~min}$ ) with either MnGTP or

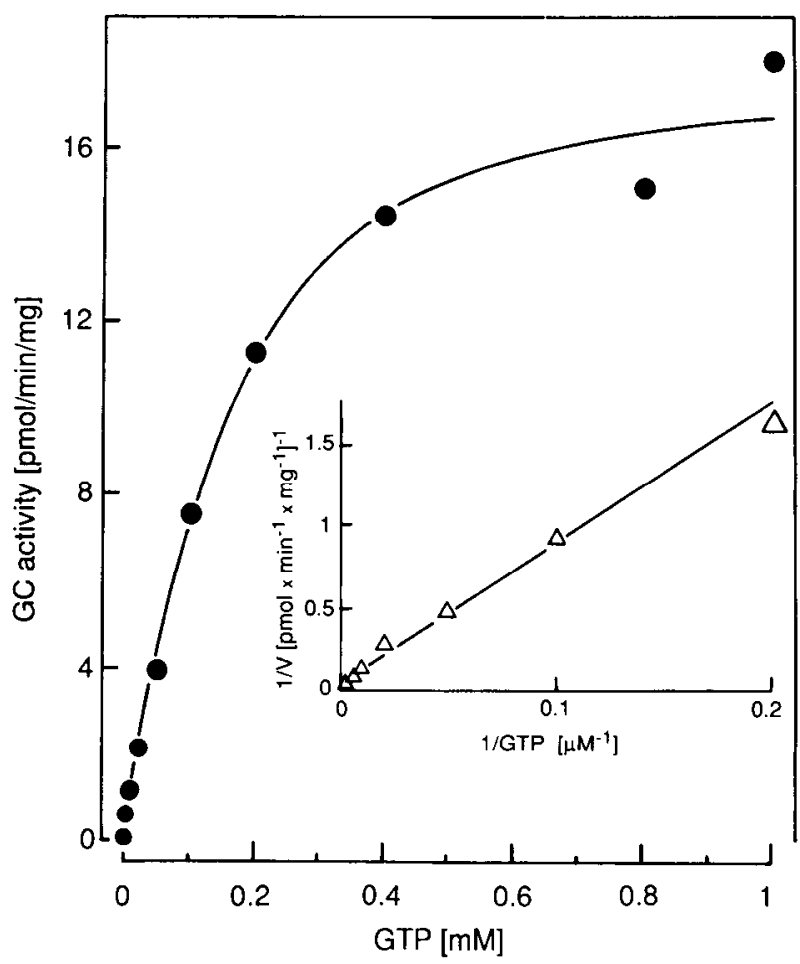

Figure 7. Michaelis-Menten kinetics for cGMP formation by GC from antennal homogenates of male moths of $A$. polyphemus. Effect of various GTP concentrations at $60 \mu \mathrm{g}$ protein and $3 \mathrm{mM} \mathrm{Mn}^{2+}$. Inset, Doublereciprocal plot (Lineweaver-Burk) of substrate kinetics.

MgGTP as substrate. Activity with the latter was only $30 \%$ of that observed with MnGTP.

The GC activity in the homogenate of antennae from $B$. mori was characterized in more detail. The enzyme displayed a sharp pII optimum at 8.25 (Fig. 6a). This effect was independent from buffer substances as it was found using Tris- $\mathrm{HCl}$, imidazole$\mathrm{HCl}$, or phosphate.

GC activity was virtually undetectable in the absence of divalent cations as cofactors. $\mathrm{Ca}^{2+}$ alone did not support activity. Highest activity was found with 1-2 $\mathrm{mM} \mathrm{Mn}{ }^{2+}$ (Fig. 6b). $\mathrm{Mg}^{2+}$, $3 \mathrm{~mm}$, as metal cofactor led to an activity of about a third of that obtained with $\mathrm{Mn}^{2+}$.

With MnGTP as substrate, antennal GC exhibited classical Michaelis-Menten kinetics (Fig. 7). Lineweaver-Burk plots were linear from 5-1000 $\mu \mathrm{M}$ GTP (Fig. 7, inset). The apparent $K_{m}$ for GTP was $175 \mu \mathrm{M}$ and $v_{\max }$ was $11 \mathrm{pmol} \times \mathrm{min}^{-1} \times \mathrm{mg}^{-1}$. Evaluation of enzyme kinetics by replotting the data according to Hanes-Woolf and Eadie-Hofstee revealed no cooperative interactions with the substrate (data not shown).

GC activity was inhibited by SH-group blocking agents such as $N$-cthylmalcimidc, $\mathrm{ZnCl}_{2}$ or $p$-hydroxymercuribenzoate. The latter compound at 10 and $100 \mu \mathrm{M}$ inhibited by 52 and $98 \%$, respectively. The inhibition was completely reversible upon addition of an excess of dithiothreitol (DTT). This indicates that the GC from moth antennae contains SH-groups necessary for enzymic activity. This was corroborated by the observation that addition of 1-5 mM DTT alone doubled enzyme activity irrespective of $\mathrm{Mn}^{2+}$ or $\mathrm{Mg}^{2+}$ as metal cofactor. Glutathion, $5 \mathrm{~mm}$, had a similar effect.

Addition of $\mathrm{Ca}^{2+}(0.1-1 \mathrm{~mm})$ with or without concomitant addition of $1-10 \mu \mathrm{g}$ calmodulin from bovine brain to the assays 
did not enhance GC activity. Similarly, atrial natriuretic factors $(1 \mu \mathrm{M})$ and neuropeptide $\mathrm{Y}(10 \mu \mathrm{M})$, peptides known to activate this enzyme in other systems, were without effect. We found a small, but consistent stimulatory effect on GC activity when $0.01-1 \mu \mathrm{g}$ bombykol was added to $20 \mu \mathrm{g}$ protein homogenate from male and female antennae (15-20\% activation). However, this could be identified as a nonspecific lipid effect since it was also apparent using similar concentrations of linoleic acid as stimulant.

Antennal homogenate was fractionated by centrifugation to see whether the enzyme is soluble. Leaving homogenized $B$. mori antennae on ice for $30 \mathrm{~min}$ resulted in separation of a yellowish upper phase containing about $30 \%$ of the protcin and settled black particulate material of the cuticle. GC activity was evenly distributed between both fractions. When these fractions were independently centrifuged at $100,000 \times g(1 \mathrm{hr}), 95 \%$ of the $\mathrm{GC}$ in the upper phase was recovered in the supernatant, whereas $80 \%$ of the GC activity in the cuticle fraction remained particulate. The latter enzyme activity could not be solubilized by sonication or by treatment with detergents or both. Al present, we have no possibility to decide whether the activities in these fractions truly represent a particulate and a soluble form of the enzyme or whether they might be due to the tough homogenization of the insect cuticle. Affinity-purified antibodies against soluble GC from bovine lung completely inhibited the "soluble" enzyme from the antennae; however, they were only partially ( $45 \%$ inhibition) effective against the "particulate" enzyme activity. This is taken as an indication that proper access of the antibodics to the cnzyme is impaired, probably because of incomplete homogenization due to the antennal cuticle.

\section{Discussion}

This study is the first report on the measurement of cyclic nucleotides and $\mathrm{GC}$ in an olfactory organ of insects. Blowing female pheromones from $A$. polyphemus and $B$. mori onto the isolated antennae of their respective males for $10 \mathrm{sec}$ led to a significant increase of cGMP of 34 and 29\%, respectively. This response was specific with regard to the pheromone of the species and to the sex of the insects, only males being responsive to female pheromones. cAMP levels were unaffected in either species and sex. We conclude that receptors for the sex pheromones in male antennae specifically mediated an elevated level of cGMP.

The advantage of our stimulation procedure lies in the wellknown electrophysiological events under our experimental conditions. Even if freezing in liquid nitrogen after the $10 \mathrm{sec}$ stimulation would take $1 \mathrm{sec}$, the receptor potential would still be above 90\% (Zack, 1979; Kaissling et al., 1987). Experiments were performed using intact animals or freshly isolated antennae. Both preparations are equally responsive to pheromone stimuli in electrophysiological tests for at least $1 \mathrm{hr}$ after severing.

However, our results do not support a role of cGMP as a functional link between pheromone interaction with presumed receptor sites at the cell membrane and receptor potential generation. First, the pheromone-induced increase in cGMP concentration shows no relation to the dose-response behavior of the receptor potential amplitude (Schneider et al., 1967; Zack, 1979; Kaissling, 1986, 1987; Zack Strausfeld and Kaissling, 1986; Kaissling et al., 1987). Second, the increased cGMP level persists for at least $10 \mathrm{~min}$ in intact animals and at least $30 \mathrm{~min}$ in isolated antennae, although the receptor potential returns within about $5 \mathrm{sec}$ after termination of the stimulus to half its resting value (Zack, 1979; Kaissling et al., 1987). It should be noted that the return of the receptor potential after a $10 \mathrm{sec}$ stimulus is not a result of adaptation because by prolonged stimulation the receptor potential amplitude can be maintained for a minute or longer at the stimulus concentration used (Kaissling, 1987). Third, no cGMP increase occurred within the sensory hairs containing the outer dendritic segments of the receptor cells. If cGMP were directly involved in the regulation of ion channels in the dendritic membranes and was, therefore, contributing to the generation of the receptor potentials, changes in CGMP in the sensory hairs should have been found. Fourth, no GC activity was found in isolated olfactory hairs. We conclude that the pheromone-specific cGMP increase possibly occurs within the soma of the olfactory neurons or even within the surrounding auxiliary cells, which in principle could control the responsiveness of the receptor neuron (Kaissling and Thorson, 1980).

From morphometrical studies on male A. polyphemus (Boeckh et al., 1960; Steinbrecht, 1970; Gnatzy et al., 1984; Keil, 1984), the number and volume of the different cell types in the antennal side branches are known. Dendrites and somata of a total of 120,000 pheromone receptor cells have a volume of $23 \mathrm{nl}$. The cell volume of the whole antenna of $149 \mathrm{nl}$ includes another 30,000 receptor cells $(5 \mathrm{nl})$, the axons of all receptor cells $(7 \mathrm{nl})$, 210,000 auxiliary cells, and an estimated 70,000 epithelial cells (together $114 \mathrm{nl}$ ). The average level of cGMP for all cells of the male antenna of $A$. polyphemus was calculated to be approximately $0.67 \mu \mathrm{M}$. The measured cGMP level in the dendrite preparation ( $50 \mu \mathrm{g}$ protein from 20 antennae) was $0.45 \mathrm{pmol} /$ mg protein, i.e., approximately $0.93 \mu \mathrm{M}$. Assuming that the total cGMP increase by $34 \%$ occurred only in dendrites and somata of the pheromone receptor cells, the average increase was calculated to be around $1.5 \mu \mathrm{mol} /$ liter, or about $1.7 \times 10^{5} \mathrm{cGMP}$ molecules/cell. If cGMP increased in all cells of the antenna, the average value for its increase in the receptor cells is 0.23 $\mu \mathrm{mol} /$ liter, or about $2.6 \times 10^{1} \mathrm{cGMP}$ molecules/cell.

These numbers are astonishingly high if one considers that a depolarization of the cell eliciting nerve impulses could already be achieved by opening of a single or a few ion channels per cell. These cells are relatively small and supposedly have a relatively high resting resistance of dendritic membrane (Kaissling and Thorson, 1980). The situation is different from the one in visual cells of vertebrates, where the ion channels are open in the dark and are closed by light stimuli. One light quantum leads to a degradation of $10^{5}$ cGMP molecules which close $3 \%$ of the open ion channels (Stryer, 1986). One would expect a much smaller amplification factor in the olfactory cells. A complete depolarization would require a number of opened channels in the range of $10^{4} /$ cell.

Villet (1978) perfused amputated antennae of Antheraea per$n y i$ with various nucleotides, including analogs, which penetrate cell membranes and phosphodicstcrase inhibitors. Pcrfusion of the hemolymph space with dibutyryl cAMP and phosphodiesterase inhibitors enhanced the electroantennogramm amplitude. Dibutyryl cGMP showed less effect than dibutyryl cAMP. From these results, Villet postulated that an increased cAMP level mediates the generation of receptor potentials in the pheromone receptor cell. Our results clearly show that this prediction is not fulfilled with respect to cAMP as well as with cGMP. In this context, we note that the presence of cyclic nucleotides as well as cyclases and phosphodiesterase in the tissue of insect taste organs has been demonstrated (Vande Berg, 1975; Felt and Vande 
Berg, 1977; Wieczorek and Schweikl, 1985). However, no changes in concentration or enzyme activity were observed after stimulation with sugar (Wieczorek and Schweikl, 1985).

Before discussing possible functions of cGMP in the antennae, we have to consider the large variability of the cGMP responses to pheromone. The strongly increased variance of data after pheromone stimulation could, in principle, be due to a large proportion (about $40 \%$ ) of nonresponsive animals. However, males of $B$. mori rarely do not respond to bombykol stimuli. Behavioral responses were more difficult to observe in $A$. polyphemus. Under our laboratory conditions we often failed to detect a behavioral response in the experimental animals of this species. However, in electrophysiological recordings from both species it is a general observation that the antennal receptor cells almost always show receptor potentials. In contrast, not for all animals does one succeed in obtaining nerve impulses, which usually fall away more rapidly in weaker animals. In this context it should be noted that the lack of a cGMP response was not due to the isolation of the antennae since it was also observed in intact insects. Furthermore, in electrophysiological studies no differences exist in the responsiveness of unadapted antennae in situ and up to $1 \mathrm{hr}$ after removal from the insect. Alternatively, all animals could have responded, but an unknown factor could have caused a superimposed variance in the cGMP level of pheromone stimulated antenna. This large variability might support the conclusion that the cGMP response is not primarily related to the receptor potential which in males is reliably generated upon each stimulation. It is noteworthy that virtually all of the isolated antennae which were tested for cGMP 5 or more min after pheromone stimulation showed a secondary cGMP increase.

A possible role of cGMP might be to modify the responsiveness of the receptor cells. Our experiments show a time scale of at least $10 \mathrm{~min}$ for the return of the cGMP level, which also applies to the recovery of the electrophysiological response after adaptation. The fact that both down-regulation of the cGMP level and the recovery of nerve impulse response were impaired after isolation of the antenna suggests a correlation of these processes. This correlation might indicate a physiological role for cGMP in the setting of parameters of the nerve impulse response. The reason for the secondary pheromone-induced increase of cGMP in isolated antennae is unknown. It is also unknown at present how cGMP could interfere with the generation of nerve impulses. The increased cGMP level does not influence the recovery of the receptor potential amplitude since the latter did not differ in intact animals and isolated antennae.

Whereas the cyclic nucleotide levels were measured after in vivo stimulation of the antennae the cyclase activity was determined in vitro. This hampers the comparison between both types of experiments. The lack of GC activity in isolated sensory hairs suggests that the cGMP found in these hairs was formed in the cell soma and moved into the dendritic segments of the receptor cell.

Although the specific activity of the insect GCs is of the same order of magnitude as that found in many metazoan tissues, the pharmacological properties - the narrow $\mathrm{pH}$ optimum and the lack of activation by $\mathrm{Ca}^{2+}$, calmodulin, atrial natriuretic factors, or neuropeptide $\mathrm{Y}$-have no resemblance to those GCs from mammalian tissues and protozoans (reviewed in Schultz and Klumpp, 1984; Waldman and Murad, 1987; Schultz and Klumpp, 1989). Nevertheless, it is remarkable from an evolutionary point of view that antibodies against soluble GC purified from bovine lung almost complctcly inhibitcd soluble enzyme activity of the antennal homogenates from $A$. polyphemus and $B$. mori. Considering the widespread occurrence of GCs in eucaryotes, it looks as if throughout evolution a GC gene as an ancestral modul has been linked to various regulatory components which are adapted to specific cellular functions.

So far, we were unable to detect adenylate cyclase and phosphodiesterase activities in the homogenates, although both enzyme activities have to be present in antennae. This failure was probably due to the harsh treatment of the antennae needed to accomplish a reasonable homogenization.

The moth antennae are highly optimized molecule sieves which effectively focus odor molecules on the olfactory hairs. The mechanical properties of the cuticular structures are serious obstacles to biochemical and more refined electrophysiological experiments. New techniques, using isolated sensory neurons, might allow one to study the function of the pheromone-induced cGMP increase. Patch-clamping of adult receptor cells or of embryonic sensory neurons in cell cultures offers the possibility of testing cGMP analogs or specific inhibitors and is now in progress (Zufall et al., 1988).

\section{References}

Anholt, R. R. H. (1987) Primary events in olfactory reception. Trends Biochem. Sci. 12: 58-62.

Avenet, P., F. Hofmann, and B. Lindemann (1988) Transduction in taste receptor cells requires cAMP-dependent protein kinase. Nature 331: 351-354.

Boeckh, J., K. E. Kaissling, and D. Schneider (1960) Sensillen und Bau der Antennengeißel von Telea polyphemus. Zool. Anat. 78: 559584.

Bradford, M. M. (1976) A rapid and sensitive method for the quantitation of microgram quantities of protein utilizing the principle of protein-dye binding. Anal. Biochem. 72: 248-254.

Felt, B. T., and J. S. Vande Berg (1977) Localization of adenylate cyclase in the blowfly labellar chemoreceptors. J. Insect Physiol. 23: 543-548.

Gnatzy, W., W. Mohren, and R. A. Steinbrecht (1984) Pheromone receptors of Bombyx mori and Antheraea pernyi: II. Morphometric data. Cell Tissue Res. 235: 35-42.

Huganir, R. L., A. H. Delcour, P. Greengard, and G. P. Hess (1986) Phosphorylation of the nicotinic acetylcholine receptor regulates its rate of desensitization. Nature 321: 774-776.

Jakobs, K. H., E. Böhme, and G. Schultz (1976) Determination of cyclic GMP in biological material. In Eucaryotic Cell Function and Growth, J. E. Dumont, B. L. Brown, and N. J. Marshall, eds., pp. 295-311, Plenum, New York.

Kaissling, K. E. (1972) Kinetic studies of transduction in olfactory receptors of Bombyx mori. In International Symposium on Olfaction and Taste, Vol. 4, D. Schneider, ed., pp. 200-206, Wissenschaftl. Verlagsgesellsch., Stuttgart.

Kaissling, K. E. (1986) Chemo-electrical transduction in insect olfactory receptors. Annu. Rev. Neurosci. 9: 121-145.

Kaissling, K. E. (1987) In R. H. Wright Lectures on Insect Olfaction, K. Colbow, ed., Simon Fraser University, Burnaby, B.C., Canada.

Kaissling, K. E., and J. Thorson (1980) Insect olfactory sensilla: Structural, chemical and electrical aspects of the functional organization. In Receptors for Neurotransmitters, Hormones and Pheromones in Insects, D. B. Sattelle, L. M. Hall, and J. G. Hildebrand, eds., pp. 261282, Elsevier/North-Holland, Amsterdam.

Kaissling, K. E., C. Zack Strausfeld, and E. R. Rumbo (1987) Adaptation processes in insect olfactory receptors: Mechanisms and behavioral significance. Ann. NY Acad. Sci. 510, Olfaction and Taste IX: $104-112$.

Keil, T. A. (1984) Reconstruction and morphometry of silkmoth olfactory hairs: A comparative study of sensilla trichodea on the antennae of male Antheraea polyphemus and Antheraea pernvi (Insecta, Lepidoptera). Zoomorphology 104: 147-156.

Klein, U., and T. A. Keil (1984) Dendritic membrane from insect 
olfactory hairs: Isolation method and electron microscopic observations. Cell. Mol. Neurobiol. 4: 385-396.

Labrarca, P., S. A. Simon, and R. R. H. Anholt (1988) Activation by odorants of a multistate cation channel from olfactory cilia. Proc. Natl. Acad. Sci. USA 85: 944-947.

Lamb, T. (1986) Transduction in vertebrate photoreceptors: The roles of cyclic GMP and calcium. Trends Neurosci. 9: 224-228.

Lancet, D., and U. Pace (1987) The molecular basis of odor recognition. Trends Biochem. Sci. 12: 63-66.

Lowry, O. H., N. J. Rosebrough, A. L. Farr, and R. J. Randall (1951) Protein measurement with the Folin phenol reagent. J. Biol. Chem. 193: 265-275.

Meng, L. Z. C. H. Wu, M. Wicklein, K. E. Kaissling, and H. J. Bestmann (1989) Number and sensitivity of three types of pheromone receptor cells in Antheraea pernyi and 4. polyphemus. J. Comp. Physiol. 165: 139-146.

Nakamura, T., and G. H. Gold (1987) A cyclic nucleotide-gated conductance in olfactory receptor cilia. Nature 325: 442-444.

Pace, U., E. Hanski, Y. Salomon, and D. Lancet (1985) Odorantsensitive adenylate cyclase may mediate olfactory reception. Nature 316: 255-258.

Schneider, D., B. C. Block, J. Boeckh, and E. Priesner (1967) Die Reaktion der männlichen Seidenspinner auf Bombykol und seine Isomeren: Elektroantennogramm und Verhalten. Z. vergl. Physiol. 54: 192-209.

Schultz, J. E., and S. Klumpp (1984) Calcium/calmodulin-regulated guanylate cyclases in the ciliary membranes from Paramecium and Tetrahymena. Adv. in Cyclic Nucleotide Protein Phosph. Res. 17: 275-283.

Schultz, J. E., and S. Klumpp (1989) Calcium-regulated guanylate cyclases from Paramecium and Tetrahymena. Methods Enzymol. (in press).

Sibley, D. R., R. J. Peters, P. Nambi, M. G. Caron, and R. J. Lefkowitz (1984) Desensitization of turkey erythrocyte adenylate cyclase. J. Biol. Chem. 259: 9742-9749.
Steinbrecht, R. A. (1970) Zur Morphometrie der Antenne des Seidenspinners, Bombyx mori L.: Zahl und Verteilung der Riechsensillen (Insecta, Lepidoptera). Z. Morphol. Tiere 68: 93-126.

Stryer, L. (1986) Cyclic GMP cascade of vision. Annu. Rev. Neurosci. 9: 87-1 19 .

Tonosaki, K., and M. Funakoshi (1988) Cyclic nucleotides may mediate taste transduction. Nature 331: 354-356.

Trotier, D., and P. MacLeod (1987) The amplification process in olfactory receptor cells. Ann. NY Acad. Sci. 510, Olfaction and Taste IX: 677-679.

Vande Berg, J. S. (1975) Cytochemical localization of phosphodiesterase: Axonal mitochondria and microtubules. J. Insect Physiol. 21 $455-461$.

Villet, R. H. (1978) Mechanism of insect sex-pheromone sensory transduction: Role of adenyl cyclase. Comp. Biochem. Physiol. 61C: 389-394.

Vodyanoy, V., and R. B. Murphy (1983) Single-channel fluctuations in bimolecular liquid membranes induced by rat olfactory epithelial homogenates. Science 220: 717-719.

Waldman, S. A., and F. Murad (1987) Cyclic GMP synthesis and function. Pharmacol. Rev. 39: 163-196.

Wieczorek, H., and H. Schweikl (1985) Concentrations of cyclic nucleotides and activities of cyclases and phosphodiesterases in an insect chemosensory organ. Insect Biochem. 15: 723-728.

Zack, C. (1979) Sensory adaptation in the sex pheromone receptor cell of saturniid moths. Dissertation Fak. Biol. Ludwig Maximilians Universität, München.

Zack Strausfeld, C., and K. E. Kaissling (1986) Localized adaptation processes in olfactory sensilla of Saturniid moths. Chem. Senses 11 . 499-512.

Zufall, F., H. Hatt, and T. A. Keil (1988) Single-channel recordings on dissociated olfactory neurons of the silkmoth Antheraea polyphemus. In Proceedings of the 16th Göttingen Neurobiology Conference, N. F. Elsner and G. Barth, eds., p. 60, Thieme, Stuttgart. 